\title{
Katmanlı Parçacıklar Kullanılarak Üretilen Bakır Esaslı Malzemelerin Karakterizasyonu
}

\author{
Temel VAROL ${ }^{1 *}$, Hüseyin Can AKSA ${ }^{2}$, Onur GÜLER ${ }^{3}$
}

\section{Öz}

Bu çalışmada, yüksek elektriksel iletkenliğe sahip ve oksidasyon direnci arttırılmış bakır esaslı elektrik malzemeleri, sıcak presleme yöntemi ile gümüş kaplı bakır tozları kullanılarak üretilmiştir. Gümüş kaplı bakır tozlarının sentezlenmesinde akımsız kaplama yöntemi kullanılmıştır. $\mathrm{Bu}$ amaçla bakır tozları, indirgeyici olarak sodyum potasyum tartarat $\left(\mathrm{C}_{4} \mathrm{H}_{4} \mathrm{O}_{6} \mathrm{KNa}_{4} \mathrm{H}_{2} \mathrm{O}\right)$ ve iyon kaynağ 1 olarak gümüş nitratın $\left(\mathrm{AgNO}_{3}\right)$ kullanıldığı akımsız gümüş banyosunda gümüş ile kaplanmıştır. Gümüş kaplı bakır tozların mikro yapısı ve morfolojisini araştırmak için taramalı elektron mikroskobu ve faz türlerini belirlemek için X-ışını kırımı kullanılmıştır. Homojen mikroyapı ve yüksek yoğunluğa sahip bakır esaslı elektrik malzemeleri, gümüş kaplı bakır tozların sıcak preslenmesi ile imal üretilmiştir. Saf bakır numunelerle karşılaştırıldığında gümüş kaplı bakır numuneler mükemmel elektrik iletkenliği (92 IACs), iyi derecede sertlik (76 Brinell) ve oksidasyon direnci ( $\% 0,281-560{ }^{\circ} \mathrm{C}$ ve 60 dak.) göstermektedir.

Anahtar Kelimeler: Katmanlı parçacıklar, Sıcak presleme, Toz metalürjisi, Akımsız kaplama, Bakır.

\section{Characterization of Copper-based Materials Fabricated Using Layered Particles}

\begin{abstract}
In this work, copper based electrical materials, which has high electrical and thermal conductivity and enhanced oxidation resistance, were fabricated from silver coated copper powders by hot pressing method. Electroless coating process was used to synthesis Ag coated copper powders. For this aim, copper powders were coated with silver in an electroless silver bath in which sodium potassium tartrate $\left(\mathrm{C}_{4} \mathrm{H}_{4} \mathrm{O}_{6} \mathrm{KNa}_{4} \mathrm{H}_{2} \mathrm{O}\right)$ and silver nitrate $\left(\mathrm{AgNO}_{3}\right)$ was used as reducing agent, source of silver ion. Scanning electron microscope for investigation of microstructure and morphology of silver coated copper powders and X-ray diffraction to determine the phase types were used. Compared with the pure Cu samples, Ag coated copper $\mathrm{Cu}$ samples exhibits excellent electrical conductivity (92 IACs), good hardness (76 BHN), and oxidation resistance ( $0,281 \mathrm{wt} \%$ at $500{ }^{\circ} \mathrm{C}$ and $60 \mathrm{~min}$.)
\end{abstract}

Keywords: Layered particles, Hot pressing, Powder metallurgy, Electroless coating, Copper.

\footnotetext{
${ }^{1}$ Karadeniz Teknik Üniversitesi, Müh. Fakültesi, Metalurji ve Malzeme Müh. Bölümü, Trabzon, Türkiye, tvarol@ktu.edu.tr ${ }^{2}$ Karadeniz Teknik Üniversitesi, Müh. Fakültesi, Metalurji ve Malzeme Müh. Bölümü, Trabzon, Türkiye, hcaksa@hotmail.com ${ }^{3}$ Karadeniz Teknik Üniversitesi, Müh. Fakültesi, Metalurji ve Malzeme Müh. Bölümü, Trabzon, Türkiye, onurguler@ktu.edu.tr
} 


\section{Giriş}

Bakır ve gümüş esaslı malzemeler yüksek elektriksel ve termal iletkenliklerinden dolayı elektronik endüstrisinde yaygın bir şekilde kullanılmaktadır. Elektrik ve elektronik malzemeleri arasında en dikkat çekici olanlar kesikli sürtünme ve ark erozyonuna maruz kalan elektrik kontak malzemeleri ve sürekli aşınmaya maruz kalan elektrik firçası malzemeleridir (Boyer ve Gall, 1985; Desforges, 1979; Nadkarni ve ark., 1984; Nystrom ve ark., 1990). Yüksek elektriksel ve termal iletkenlik, yüksek aşınma direnci ve iyi oksidasyon direnci, bu tür malzemeler için gerekli özelliklerdir (ASM Metals Handbook, 1990; Chen ve Sawa, 1996; Coxe ve ark., 1990). Yap1lan araştırmalar, bakır parçacıkların oksidasyon direncinin ve yüzey özelliklerinin iyileştirilmesi için farklı kaplama yöntemleri olduğunu göstermektedir. Yapılan bu kaplama işlemleriyle birlikte yüksek sıcaklık aralığına sahip uygulamalar da dâhil olmak üzere elektrik-elektronik sektöründe yüksek maliyetli gümüş kullanımı yerine oksidasyon direnci arttırılmış, yüksek elektriksel ve termal iletkenlik özelliklerine sahip gümüş kaplı bakır parçacıklarının kullanılabileceğini göstermektedir (Ang ve ark., 2004; D. Jeannot, 1994). Kaplama işlemi olarak elektrolitik kaplama, akımsız kaplama, fiziksel (PVD) ve kimyasal (CVD) buhar biriktirme yöntemi gibi farklı yöntemler kullanılmaktadır. Bununla birlikte fiziksel ve kimyasal buhar biriktirme yöntemi için oldukça yüksek maliyetli cihazlara ihtiyaç duyulmaktadır (Perelaer ve ark., 2008). Elektrolitik kaplamanın, homojen yüzey kaplamasını sağlayamaması ve toz numunelere uygulanamamasından dolayı metalik toz kaplama işlemlerinde akımsız kaplama yöntemi tercih edilmektedir. Akımsız kaplama işlemi, kaplanan parçanın bütün yüzeyi boyunca homojen kaplama tabakası elde edilmesine ek olarak yüksek verim ve yüksek malzeme biriktirme özelliğiyle de diğer kaplama yöntemlerine göre üstünlük sağlamaktadır (Güler ve ark., 2019; Lim ve ark., 2016; Meng ve ark., 2017).

Katmanlı malzeme kullanımı elektrik ve elektronik sektöründe mevcut olmakla birlikte bu tür malzemeler ince metal plakaların birbiri üzerine difüzyon yöntemi ile tutturulması şeklinde üretilmektedir. Bu tür üretim şekli oldukça uzun işlem süresi ve proses maliyeti içermekte ve katmanlı tozların yoğunlaştırılması ile üretilen elektrik malzemelerinde bu olumsuzluklar önemli oranda ortadan kaldırılmaktadır (Güler, Alver ve Varol, 2020; Güler, Varol, Alver ve Çanakçı, 2020). Metal ve bimetalik tozlarının şekillendirilmesinde, tek veya çift yönlü presleme, soğuk izostatik presleme ve sıcak izostatik presleme, sıcak presleme, toz enjeksiyon kalıplama ve ekstrüzyon teknikleri gibi farklı teknikler kullanılarak oldukça kısa üretim süreçlerinde nihai malzeme üretilebilmektedir (Biswas ve ark., 2018; Canakci ve ark., 2012; Canakci ve ark., 2013; G., 2007; Günay, 2009; Mutlu, 2011; Rudnik ve Jucha, 2013).

$\mathrm{Bu}$ çalışmada, geleneksel iletken malzeme üretim yöntemlerine alternatif olarak geliştirilen 
katmanlı metal tozu kullanımı araştırılmıştır. Bu çalışmanın amacı katmanlı tozlar kullanılarak üretilen $\mathrm{Cu}$-Ag iletken malzemelerinin üretimi ile fiziksel ve mekanik özelliklerinin karakterize edilmesidir.

\section{Materyal ve Metot}

$\mathrm{Bu}$ çalışmada başlangıç malzemesi olarak küresel morfolojiye sahip ortalama toz boyutu $28 \mu \mathrm{m}$ olan bakır tozları kullanılmıştır. Akımsız kaplama işlemi öncesi bakır toz yüzeylerindeki oksit oluşumlarını gidermek için kullanılan oksit temizleme çözeltisi amonyum sülfat $\left(\left(\mathrm{NH}_{4}\right)_{2} \mathrm{SO}_{4}\right)$ ve amonyak $\left(\mathrm{NH}_{3}\right)$ kullanılarak hazırlanmıştır. Akımsız kaplama işleminde gümüş kaynağı olarak Gümüş Nitrat $\left(\mathrm{AgNO}_{3}\right)$, gümüş iyon yakalayııı (indirgeyici) olarak Sodyum Potasyum Tartarat $\left(\mathrm{C}_{4} \mathrm{H}_{4} \mathrm{KNaO}_{6} .4 \mathrm{H}_{2} \mathrm{O}\right)$ ve $\mathrm{pH}$ dengeleyici olarak Amonyum Hidroksit $\left(\mathrm{NH}_{4} \mathrm{OH}\right)$ kullanılmıştır.

0,025 Molar $\mathrm{C}_{4} \mathrm{H}_{4} \mathrm{KNaO}_{6} .4 \mathrm{H}_{2} \mathrm{O} 50 \mathrm{~mL}$ 'lik sulu çözelti haline getirilmiş ve bu çözelti 600 devir/dakika karıştırma hızı ile $40{ }^{\circ} \mathrm{C}$ sıcaklığa ulaşıncaya kadar karıştırılmıştır. Çözelti sıcaklığının $40{ }^{\circ} \mathrm{C}$ 'ye ulaşması ile oksitten arındırılmış $\mathrm{Cu}$ tozları çözeltiye eklenmiştir ve 600 devir/dakika karıştırma hızında karıştırma sürdürülmüştür. Akımsız gümüş kaplama işleminde gümüş iyon kaynağı olarak kullanılan $\mathrm{AgNO}_{3}(0,025 \mathrm{M}) 50$ mL'lik sulu çözelti haline getirilmiş ve $40{ }^{\circ} \mathrm{C}^{\text {’ye }}$ ulaşana kadar 600 devir/dakika karıştırma hızı ile karıştırılmıştır. Gümüş iyon kaynağı çözeltisinin sıcaklığının $40^{\circ} \mathrm{C}$ 'ye ulaşması ile çözeltinin pH'ını düzenlemek amacıyla $\mathrm{NH}_{4} \mathrm{OH}$ çözeltisi pH değeri 11 oluncaya kadar çözeltiye ilave edilmiş ve çözeltinin pH değerinin 11 olmasıyla birlikte akımsız kaplama işlemi uygulanmıştır. Aşağıda verilen Denklem 1 ve Denklem 2 akımsız gümüş kaplama işleminde sırasıyla pH düzenlemek amacıyla ilave edilen $\mathrm{NH}_{4} \mathrm{OH}$ çözeltisi ile $\mathrm{AgNO}_{3}$ çözeltisi arasındaki kimyasal tepkimeleri, Denklem 6 ise gümüş kaynağı ile iyon yakalayıcı(indirgeyici) arasında meydana gelen kimyasal tepkimeleri göstermektedir.

$$
\begin{aligned}
& 2 \mathrm{NH}_{4} \mathrm{OH}+2 \mathrm{AgNO}_{3} \rightarrow \mathrm{Ag}_{2} \mathrm{O}+\mathrm{H}_{2} \mathrm{O}+2 \mathrm{NH}_{4} \mathrm{NO}_{3} \\
& \mathrm{Ag}_{2} \mathrm{O}+4 \mathrm{NH}_{4} \mathrm{OH} \rightarrow 2\left[\mathrm{Ag}\left(\mathrm{NH}_{3}\right)_{2}\right] \mathrm{OH}+3 \mathrm{H}_{2} \mathrm{O} \\
& 3 \mathrm{Ag}_{2} \mathrm{O}+\mathrm{C}_{4} \mathrm{H}_{4} \mathrm{O}_{6}+2 \mathrm{OH} \rightarrow 6 \mathrm{Ag}+2 \mathrm{C}_{2} \mathrm{O}_{4}+3 \mathrm{H}_{2} \mathrm{O}
\end{aligned}
$$

Kaplanmamış ve gümüş kaplı bakır tozları argon atmosferi ortamında 400, 500 ve $600{ }^{\circ} \mathrm{C}$ sıcaklıklarda $500 \mathrm{MPa}$ basınç altında 2 saat süre ile sıcak presleme işlemine tabi tutularak yoğunlaştırma işlemine tabi tutularak bakır esaslı iletken malzemeler üretilmiştir. Bu çalışmada yapılan tüm deneysel çalışmalar ve karakterizasyon işlemleri Şekil 1'de şematik olarak gösterilmiştir. 

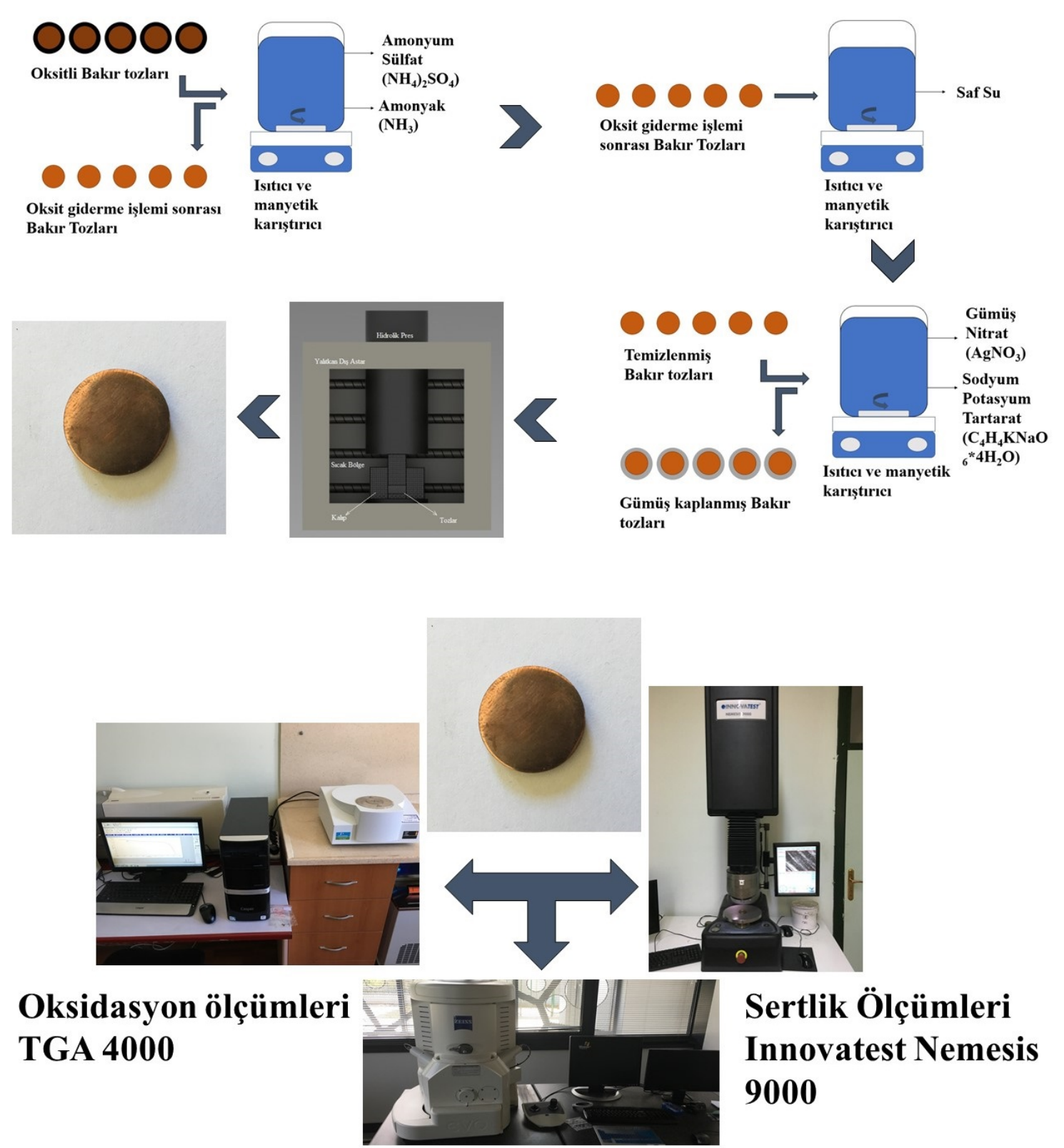

Taramalı Elektron Mikroskobu (SEM) ve EDS

Şekil 1. Çalışma kapsamında gerçekleştirilen üretim yöntemleri ve deneylerin şematik gösterimi.

Kaplanmamış Cu parçacıklarına ait morfolojiler ve sıcak presleme yöntemiyle üretilmiş bakır esaslı iletken malzemelerin içyapıları incelemeleri Zeiss Evo LS10 marka taramalı elektron mikroskobu (SEM) kullanılarak araştırılmıştır. Sertlik Deneyleri, INNNOVATEST Universal Hardness Tester Nemesis 9000 cihazında gerçekleşmiştir. Numunelerin sertliğini incelemek için, 15 sn boyunca $31,25 \mathrm{~kg}$ yük altında $2.5 \mathrm{~mm}$ çapında çelik bilye ile brinell sertlik yöntemi kullanılmıştır. Son olarak bakır parçacıkların ve bimetal parçacıkların oksidasyon davranışları $10^{\circ} \mathrm{C} / \mathrm{dk}^{-1} 1 \mathrm{~s} ı$ tma hızında termogravimetrik analiz (TGA) kullanılarak incelenmiştir. Elektriksel iletkenlik değerleri \% IACS (Uluslararası Tavlı Bakır Standartları) değerinde verilmiştir. 


\section{Bulgular ve Tartışma}

\subsection{Morfoloji}

Şekil 2a kaplama işlemi uygulanmamış bakır parçacıkların, Şekil 2b-c ise gümüş kaplı bakır parçacıklara ait morfolojileri göstermektedir. Şekil 2c aynı zamanda bakır çekirdek üzerindeki gümüş kabuk veya kaplama tabakasının kalınlığını göstermektedir. Şekil 2'den de anlaşılacağı üzere gümüş kaplama tabakası küresel bakır morfolojisine uygun şekilde küresel olarak bakır yüzeyine birikerek homojen bir kaplama tabakası oluşturmuştur. Şekil 2c'de görüldüğü gibi akımsız kaplama yöntemi ile 1-3 $\mu \mathrm{m}$ aralığında değișen bir kabuk kalınlığına sahip kaplama tabakası bakır çekirdek üzerinde oluşturulmuştur.

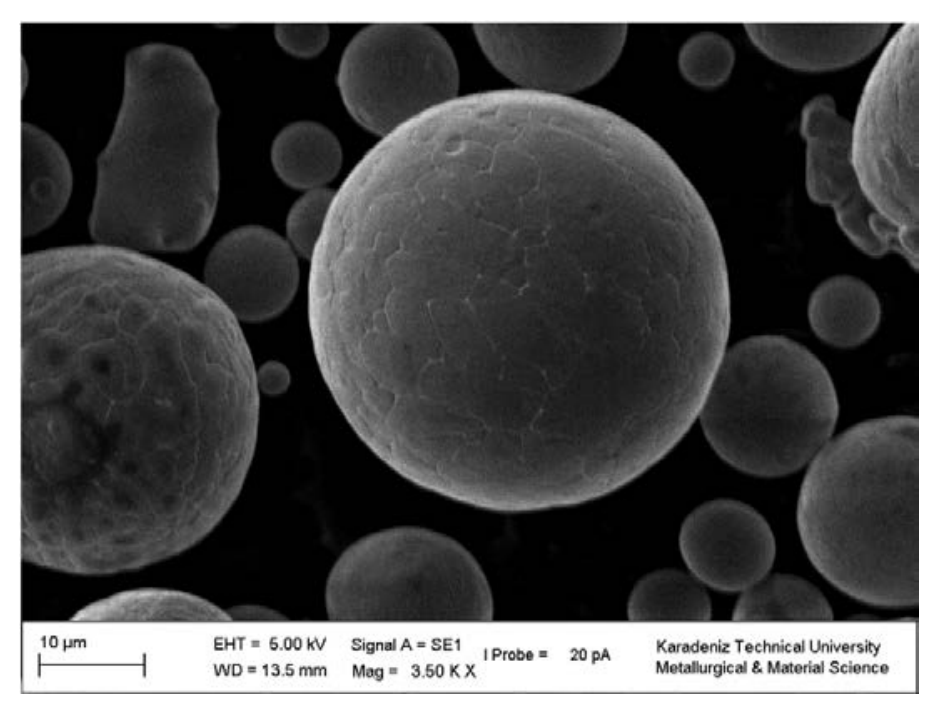

(a)

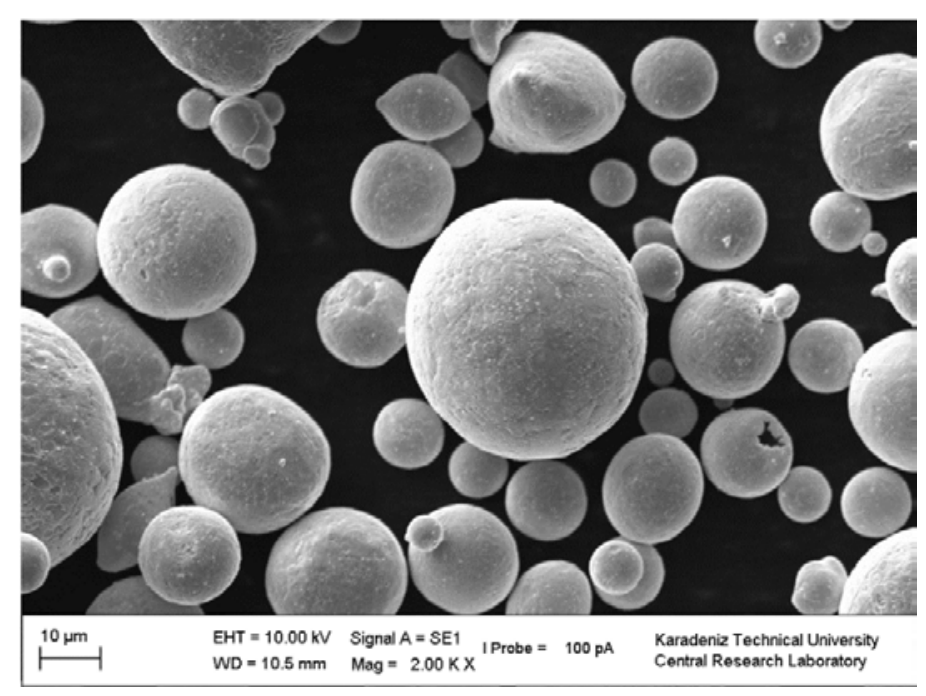

(b) 


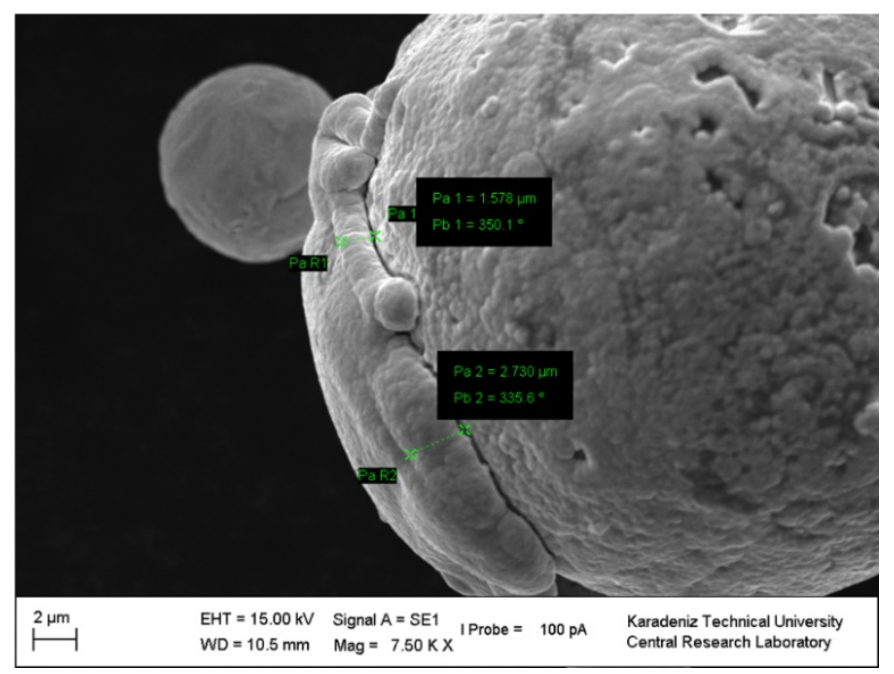

(c)

Şekil 2. (a) Bakır tozlarına ait başlangıç morfolojisi, (b) gümüş kaplı bakır tozlarına ait genel morfoloji ve (c) bakır parçacık üzerine kaplı gümüş katman morfolojisi

\subsection{Mikroyapı}

Şekil 3 gümüş kaplı bakır parçacıkların sıcak presleme işlemi ile yoğunlaştırılması sonucu üretilen iletken malzemelere ait farklı büyütmelerdeki içyapı resimlerini içermektedir. Akımsız kaplama yöntemi ile bakır parçacıkların yüzeyinde sentezlenen gümüş kaplama tabakası içyapı resimlerinde görüldüğü gibi bakır parçacıkların tane sınırlarını çevreleyecek şekilde gümüş ağ yapısına dönüşmüştür. Gümüş ağ yapısının kalınlığı morfoloji resimlerinde gözlemlenen kaplama tabakası kalınlığını doğrulamaktadır. İletken malzeme içyapısında bulunan ve bakır tanelerini çevreleyen gümüş ağ yapısı iletken malzemenin hem iletkenlik değerlerini yükseltmekte hem de oksidasyon direncini iyileştirmektedir.

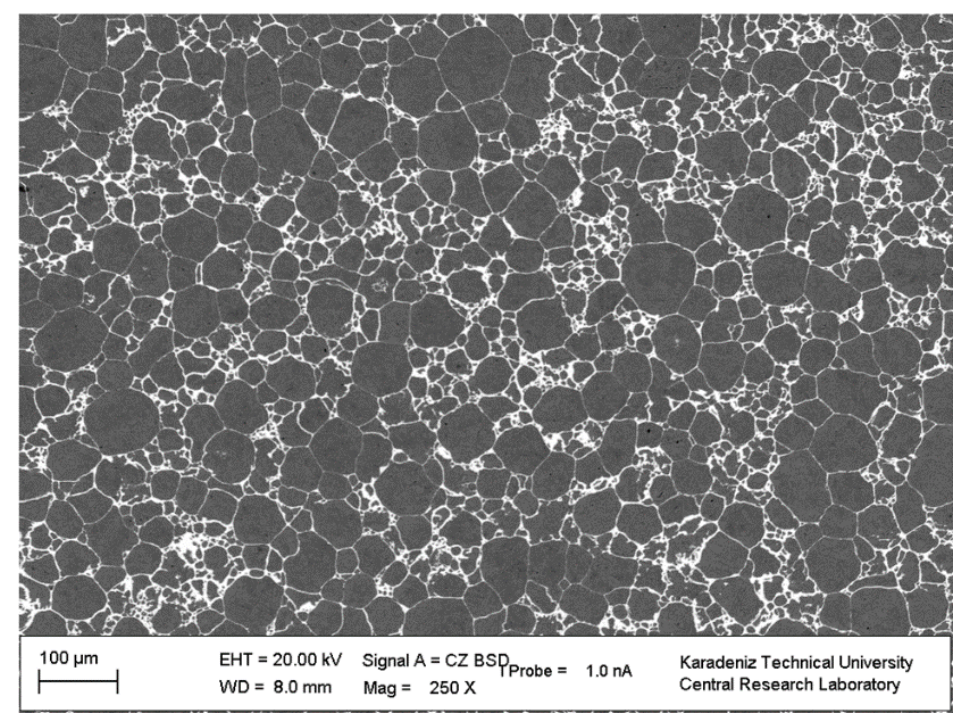

(a) 


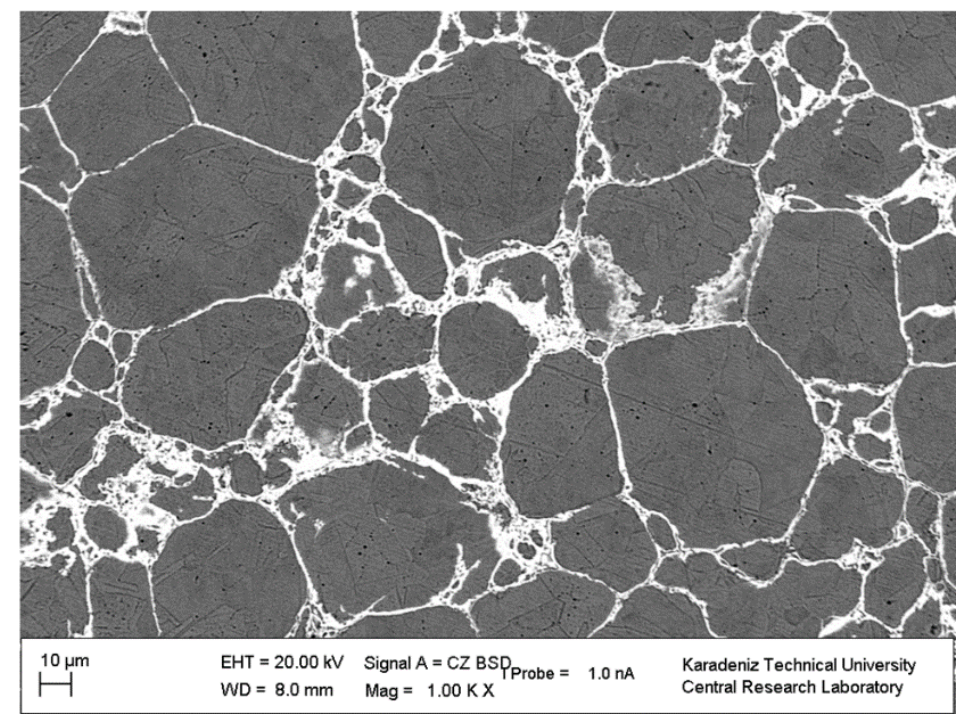

(b)

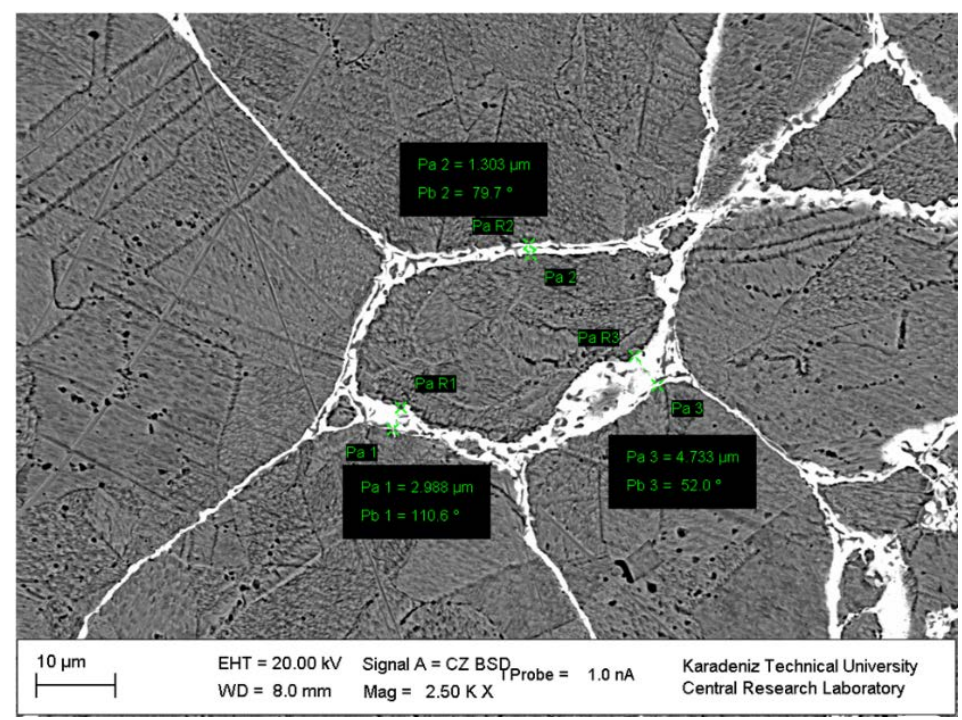

(c)

Şekil 3. Gümüş ağ yapısını içeren iletken malzeme içyapısı; (a) 250x, (b) 1000x ve (c) 2500x büyütme

Şekil 4'te gümüş ağ yapısının malzeme içyapısındaki homojen dağılımını gösteren elementsel haritalama resimleri görülmektedir. Elementsel haritalama resimlerinden de anlaşıldığı gibi kırmızı ton ile belirtilen bölgeler bakır çekirdeği, yeşil ton ile gösterilen bölgeler ise gümüş ağı ifade etmektedir. İncelemeler kapsamında herhangi bir bakır oksit varlığı gözlemlenmemiştir. 


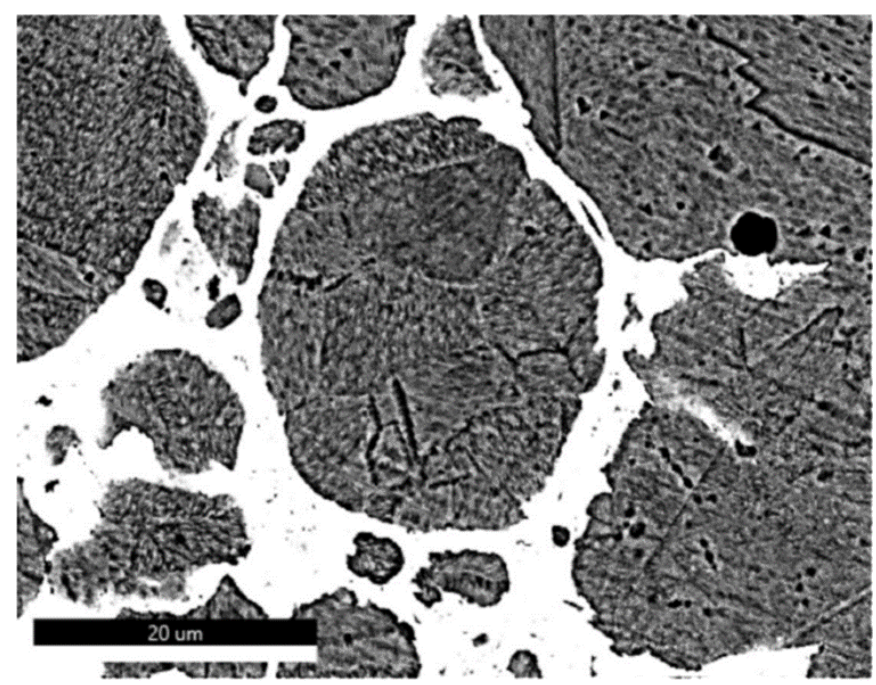

(a)

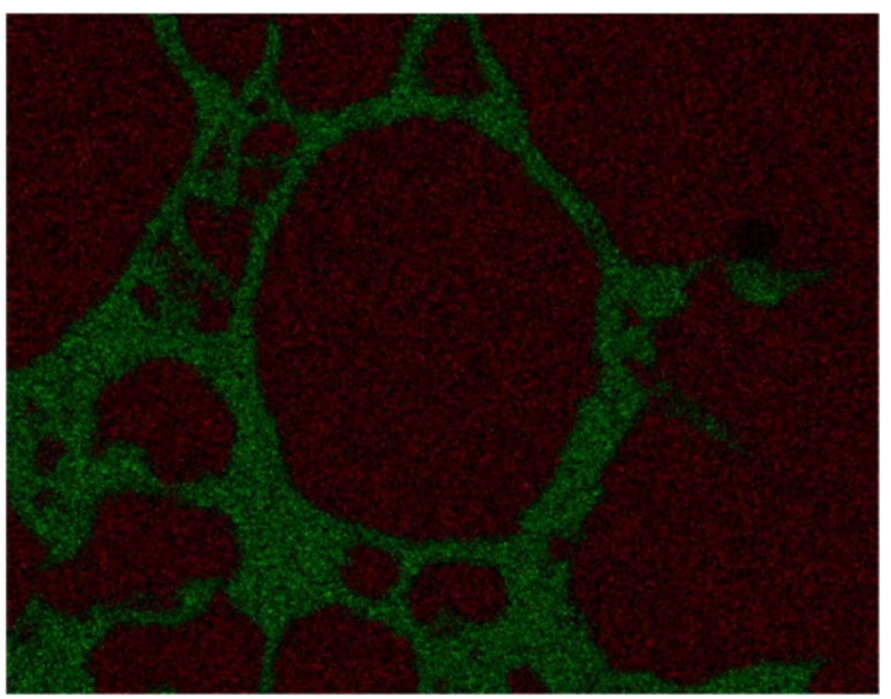

(b)

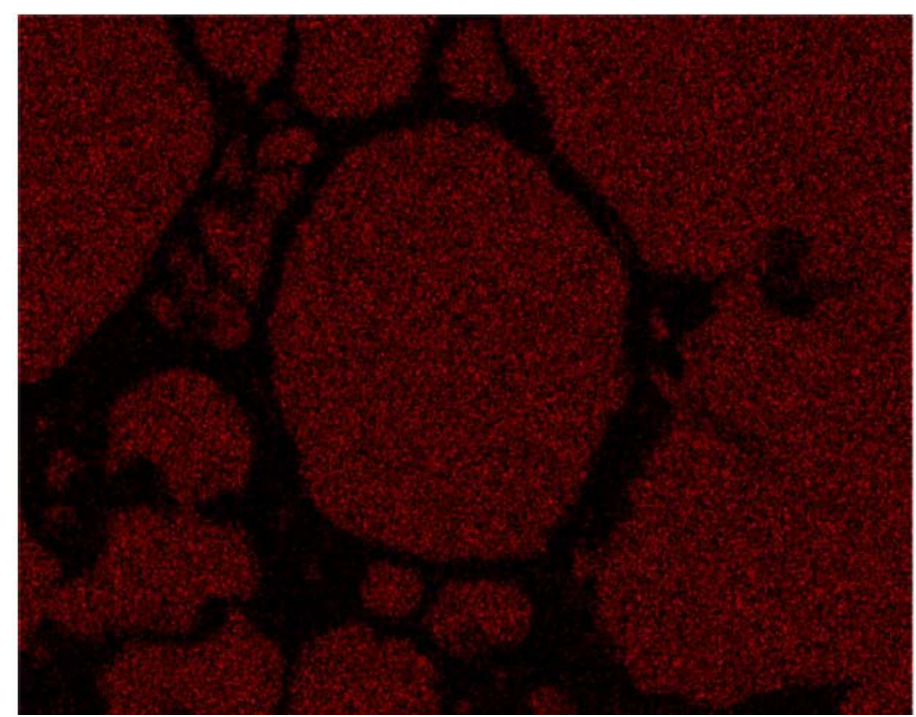

(c) 


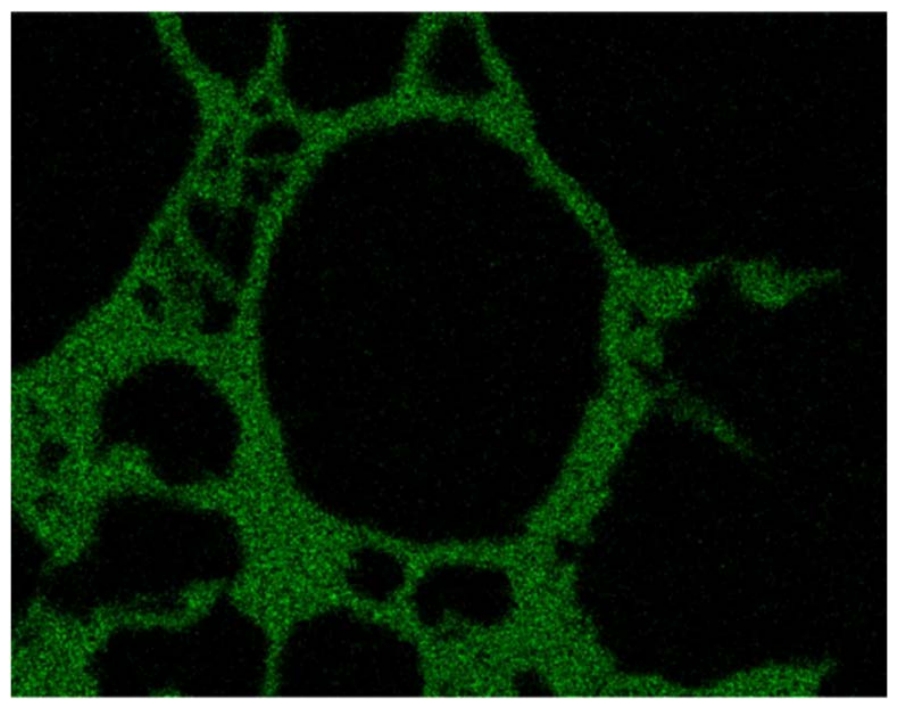

(d)

Şekil 4. İletken malzeme içyapısında gümüş ağ yapısının dağılımını gösteren elementel haritalama resimleri; (a) genel içyapı resmi, (b) Cu-Ag elementsel haritalama resmi, (c) Bakır matris dağılımı ve (d) Gümüş ağ dağılımı

\subsection{Sertlik}

Şekil 5 bakır esaslı iletken malzemelerde artan sıcaklığa bağlı olarak sertlik değerlerindeki değişimi göstermektedir. Şekil 5’te görüldüğü gibi artan sıcaklıkla birlikte sertlik değerleri artmakta bununla birlikte artış eğilimi artan sıcaklıkla azalmaktadır. Artan sıcaklıkla sertlik değerlerindeki artışın sebebi azalan gözenek miktarıdır. $500{ }^{\circ} \mathrm{C}$ sonrası sertlik artış eğilimindeki azalmanın sebebi gözenek miktarının giderek azalması ve malzemenin yeterli yoğunluğa ulaşma eğilimine girmesidir. Sertlik sonuçlarında dikkat çekici bir diğer nokta ise döküm yöntemi ile üretilen saf bakır malzemelere göre sertlik değerlerinin yüksek oluşudur. Bu durum hızlı katılaştırma yöntemi ile üretilen metalik toz yapısından ve sıcak presleme etkisinin tavlamadan ziyade yoğunlaştırma etkisi göstermesinden kaynaklanmaktadır. Saf bakır için 400, 500 ve $600^{\circ} \mathrm{C}$ 'de elde edilen sertlik değerleri sırasıyla, 54, 75 ve 82 Brinell olarak ölçülmüştür. Saf bakır için elde edilen sertlik değerlerinin gümüş kaplı bakır kullanılarak üretilen iletken malzemelerden yüksek olmasının sebebi gümüş'ün bakıra nazaran daha düşük sertliğe sahip olmasıdır. 


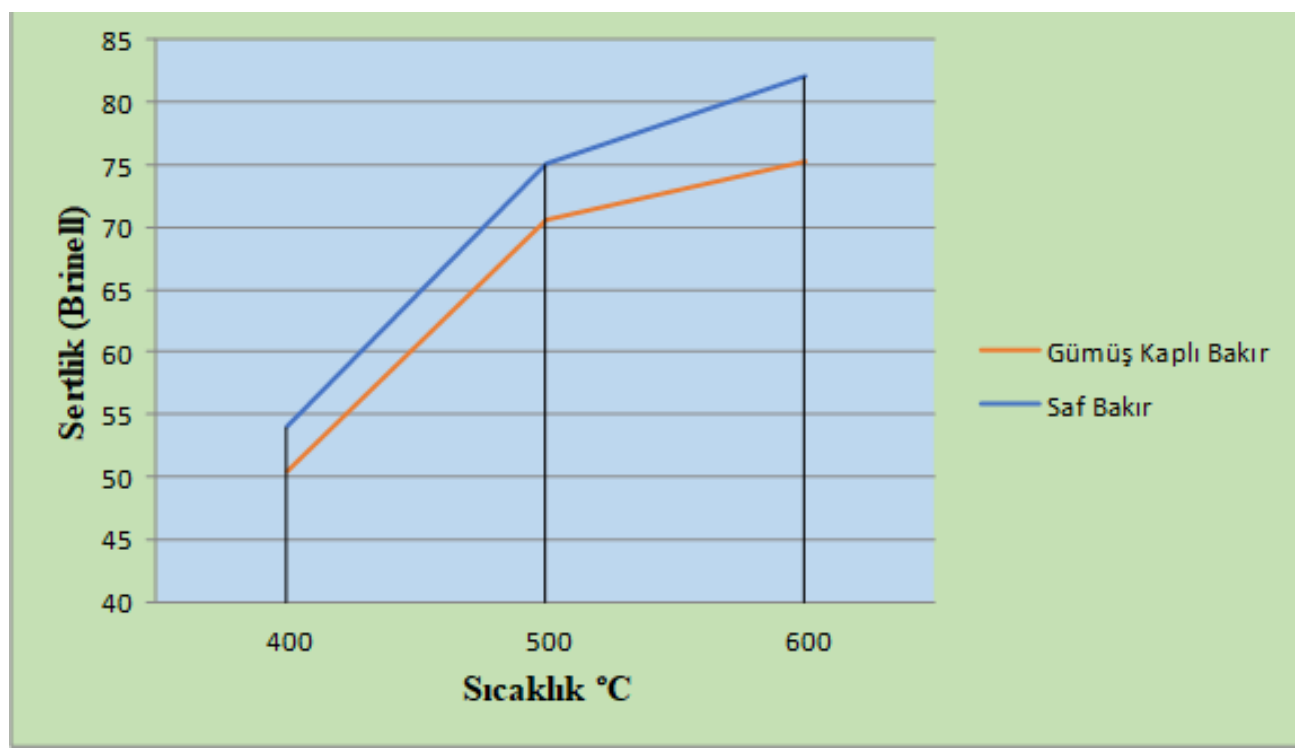

Şekil 5. $500 \mathrm{MPa}$ basınç altında gerçekleştirilen sıcak presleme işleminde sıcaklığa bağlı olarak sertlik değerlerinin değişimi.

\subsection{Elektriksel İletkenlik}

İletken malzemeler için en önemli özelliklerden biri olan elektriksel iletkenlik seviyesi aynı zamanda üretilen veya geliştirilen malzemenin kullanım alanını belirlemektedir. Şekil 6' da gümüş ağ yapısına sahip bakır esaslı iletken malzemenin presleme sıcaklığı ile elektriksel iletkenlik değerindeki değişim görülmektedir. Şekil 6'da görüldüğü gibi elektriksel iletkenlik değerleri artan presleme sıcaklığı ile lineer olarak artmakta ve 78 IACS ile 92 IACS arasında değerleri elde edilmektedir. Saf bakır için 400,500 ve $600{ }^{\circ} \mathrm{C}$ 'de elde edilen iletkenlik değerleri sırasıyla, 70,76 ve 85 IACS olarak ölçülmüştür. Elde edilen iletkenlik değerlerinden de anlaşıldığı üzere gümüş kaplı bakır tozları kullanımı ile iletkenlik değerleri daha yüksek seviyelere çıkarılmıştır. 


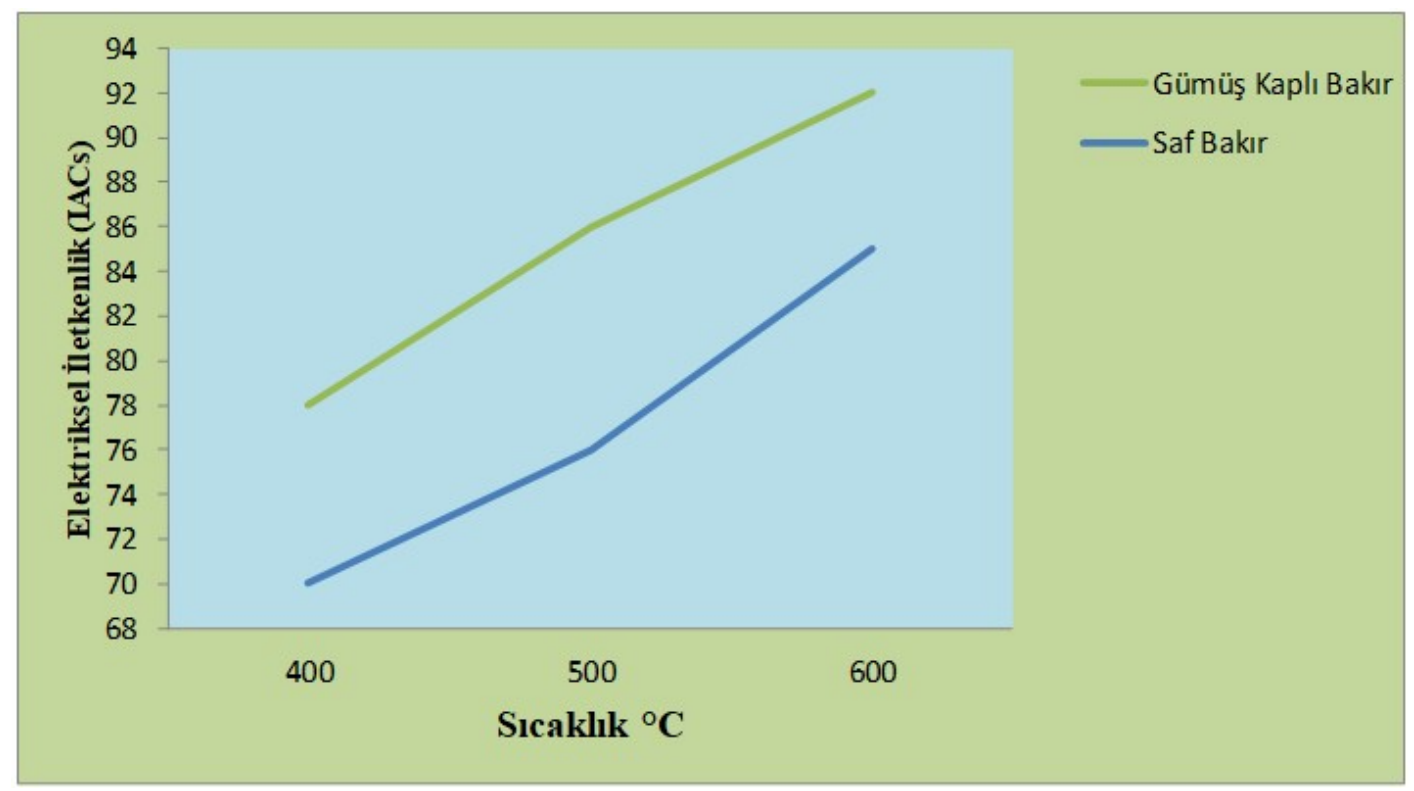

Şekil 6. 500 MPa basınç altında gerçekleştirilen sıcak presleme işleminde sıcaklığa bağlı olarak iletkenlik değerlerinin değişimi.

\subsection{Oksidasyon Direnci}

Şekil 7'de $500{ }^{\circ} \mathrm{C}$ sıcaklık ve $500 \mathrm{MPa}$ sıcak presleme basıncı şartlarında üretilen saf bakır ve gümüş kaplı bakır numunelere $600{ }^{\circ} \mathrm{C}$ sıcaklıkta uygulanan oksidasyon deneyi sonuçları görülmektedir. Şekil 7'de gözlemlendiği gibi artan bekleme süresi ile bakır ve gümüş kaplı bakır numunelerde oksidasyona bağlı olarak ağırlık artışı gözlemlenmiştir. Bununla birlikte gümüş kaplı bakır tozlar kullanılarak üretilen iletken malzemeler oksidasyona karşı iyi derecede direnç göstermektedir. $600{ }^{\circ} \mathrm{C}$ sıcaklıkta ve 60 dakika bekleme süresi sonunda gümüş kaplı bakır malzeme saf bakıra göre neredeyse üç kat daha iyi oksidasyon direnci göstermiştir. $\mathrm{Bu}$ sonuç gümüş kaplamanın bakır tozları ve bu tozlar kullanılarak üretilen iletken malzemelerin oksidasyon dirençlerinin ne derecede geliştirilebileceği açısından oldukça önemlidir. 


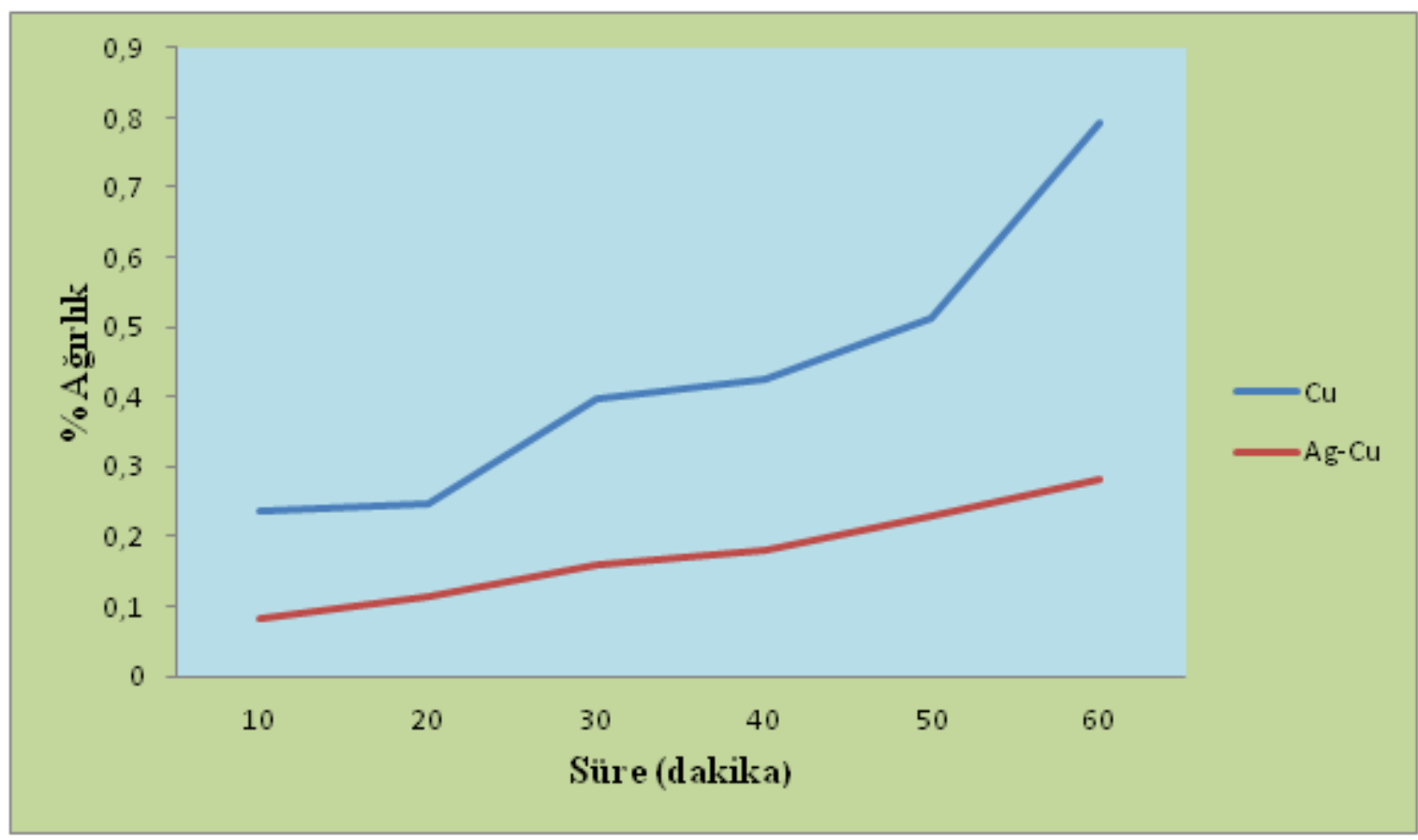

Şekil 7. $600{ }^{\circ} \mathrm{C}$ sıcaklıkta bekleme süresine bağlı olarak numune ağırlıklarındaki değişim

\section{Sonuçlar ve Öneriler}

Bu çalışmada saf bakır tozları akımsız kaplama yöntemi ile gümüş kaplanmış ve akabinde sıcak presleme tekniği ile yoğunlaştırılarak hem iletken hem de yüksek oksidasyon direncine sahip bakır esaslı iletken malzemeler üretilmiştir. Buna göre çalışmanın özgün sonuçları;

1) Akımsız kaplama yöntemi ile bakır partikülleri üzerinde 1-3 $\mu \mathrm{m}$ kalınlığında gümüş kaplama tabakası sentezlenmiştir.

2) Sıcak presleme tekniği kullanılarak üretilen bakır esaslı iletken malzeme içyapısı incelendiğinde gümüş kaplama tabakasının bir ağ biçiminde bakır matrisi sardığı ve bütün içyapıya homojen bir şekilde dağıldığı gözlemlenmiştir.

3) Artan presleme sicaklığı ile numunelerde daha iyi sertlik ve iletkenlik değerleri gözlemlenmiştir. En yüksek sertlik değeri 76 Brinell ve en yüksek iletkenlik değeri ise 92 IACS olarak ölçülmüştür. Bu değerler çalışma kapsamında üretilen bakır esaslı iletken malzemelerin elektrik ve elektronik uygulamalarda kullanımı için mükemmel değerlerdir.

4) Gümüş kaplı bakır numuneler bakır esaslı numunelere göre hemen hemen 3 kat daha iyi oksidasyon direnci göstermiş olup böylelikle bu çalışma sonucunda bakır esaslı malzemelerin oksidasyon kaynaklı kullanımlarını engelleyen kısıt ortadan kaldırılmıştır. 


\section{Teşekkür}

Bu çalışma, TÜBİTAK tarafından 119M398 numaralı proje ile maddi olarak desteklenmiştir. Makalenin inceleme ve değerlendirme aşamasında yapmış oldukları katkılardan dolayı editör ve hakem/hakemlere teşekkür ederiz.

\section{Kaynaklar}

Ang, T. P., Wee, T. S. A. and Chin, W. S. (2004). Three-Dimensional Self-Assembled Monolayer (3D SAM) ofn-Alkanethiols on Copper Nanoclusters. The Journal of Physical Chemistry B, 108(30), 11001-11010. doi:10.1021/jp049006r

ASM Metals Handbook. (1990). (T. B. Zorc Ed. Vol. 2).

Biswas, N., Baranwal, R. K., Majumdar, G. and Brabazon, D. (2018). Review of duplex electroless coatings and their properties. Advances in Materials and Processing Technologies, 4(3), 448-465. doi:10.1080/2374068x.2018.1457298

Boyer, H. E., \& Gall, T. L. (1985). Metals handbook; desk edition.

Canakci, A., Varol, T. and Ertok, S. (2012). The effect of mechanical alloying on Al2O3 distribution and properties of Al2O3 particle reinforced Al-MMCs. Science and Engineering of Composite Materials, 19(3), 227-235. doi:10.1515/secm-2011-0122

Canakci, A., Varol, T. and Nazik, C. (2013). Effects of amount of methanol on characteristics of mechanically alloyed Al-Al2O3composite powders. Materials Technology, 27(4), 320-327. doi:10.1179/1753555712y.0000000014

Chen, Z.-K. and Sawa, K. (1996). Characteristics of Ag contact morphology in breaking arcs. Wear, 199(2), 237-244. doi:10.1016/0043-1648(96)06971-2

Coxe, C., McDonald, A., Sistare, G., Lampman, S. and Zorc, T. (1990). Metals Handbook.

D. Jeannot, J. P., P. Ramoni and E.M. Jost. (1994). Physical and chemical properties of metal oxide additions to Ag-SnO2 contact materials and predictions of electrical performance. IEEE Transactions on Components, Packaging, and Manufacturing Technology, Part A, 17(1), 17-23.

Desforges, C. J. P. M. (1979). Sintered materials for electrical contacts. 22(3), 138-144.

G., R. M. (2007). Toz Metalurjisi ve Parçacıklı Malzeme İşleme (M. T. v. N. D. Süleyman Sarıtaş, Trans.). Ankara: Toz Metalurjisi Derneği Yayınları.

Güler, O., Varol, T., Alver, Ü. and Çanakçı, A. (2019). The effect of flake-like morphology on the coating properties of silver coated copper particles fabricated by electroless plating. Journal of Alloys and Compounds, 782, 679-688. doi:10.1016/j.jallcom.2018.12.229

Güler, O., Alver, Ü. and Varol, T. (2020). Fabrication and characterization of novel layered materials produced by electroless plating and hot pressing. Journal of Alloys and Compounds, 835, 155278. doi: 10.1016/j.jallcom.2020.155278

Güler, O., Varol, T., Alver, Ü., and Çanakçı, A. (2020) Effect of A12O3 content and milling time on the properties of silver coated $\mathrm{Cu}$ matrix composites fabricated by electroless plating and hot pressing. Materials Today Communiations, 24, 101153. doi: 10.1016/j.mtcomm.2020.101153

Günay, M. (2009). Toz metalurjisi yöntemiyle üretilmis Al-Si/SiCp kompozitlerin mekanik ve işlenebilirlik özelliklerinin araştırılması. Gazi Üniversitesi, Fen Bilimleri Enstitüsü, Ankara.

Lim, Y., Lee, C., Choi, H., and Bae, J. (2016). Fabrication of electrically conductive substrates using copper nanoparticles-deposited carbon black. Journal of Composite Materials, 51(18), 2597-2605. doi:10.1177/0021998316674266

Meng, D. R., Wang, L. M., Zhang, J. G., Hu, Q., Wang, L. G., and Li, C. F. (2017). Process and Properties of Ultrafine Silver-Coated Electrolytic Copper Powders. Materials Science Forum, 898, 898-907. doi:10.4028/www.scientific.net/MSF.898.898

Mutlu, İ. (2011). Toz metalurjisi yöntemiyle elde edilen gözenekli martenzitik paslanmaz çeliğin mikroyapısı ve mekanik özellikler. İstanbul Üniversitesi, Fen Bilimleri Enstitüsü, İstanbul. 
Nadkarni, A., Synk, E., Gilman, P., Benjamin, J., Mills, K., Davis, J., . . Sanders, B. J. P. M. A., Metals Park.-OH. (1984). Metals handbook.

Nystrom, W. A. in New Perspectives in Powder Metallurgy (P. W. Taube-nblat Ed. Vol. 7). Princeton, NJ: Metal Powder Industries Federation.

Perelaer, B. J., de Laat, A. W. M., Hendriks, C. E., and Schubert, U. S. (2008). Inkjet-printed silver tracks: low temperature curing and thermal stability investigation. Journal of Materials Chemistry, 18(27). doi:10.1039/b720032c

Rudnik, E., and Jucha, T. (2013). Electroless and electrolytic deposition of Co-SiC composite coatings on aluminum. Surface and Coatings Technology, 232, 389-395. doi:10.1016/j.surfcoat.2013.05.040

Shen, Y., Lattari, P., Gardner, J., and Wiegard, H. J. A. I. M. P., OH. (1990). ASM Metals Handbook (Vol. 2). 